\begin{tabular}{|c|c|c|}
\hline $\begin{array}{l}\text { Incorporación infanto-juvenil a } \\
\text { la fuerza internacional de } \\
\text { trabajo: el caso costarricense a } \\
\text { partir de datos suministrados } \\
\text { por el X Censo de Población y } \\
\text { VI de Vivienda, } 2011\end{array}$ & $\begin{array}{l}\text { Child and Adolescent } \\
\text { Integration to International } \\
\text { Labour: The Case of Costa Rica } \\
\text { Based on Supplied Data by the } \\
X \text { Census of Population and VI } \\
\text { of Housing. 2011. }\end{array}$ & $\begin{array}{l}\text { Artículo recibido: } \\
18 \text { de febrero del } 2016 . \\
\text { Evaluado: } \\
28 \text { de marzo del } 2016 . \\
\text { Aceptado: } \\
29 \text { de abril del } 2016 .\end{array}$ \\
\hline
\end{tabular}

RESUMEN

Se problematiza la incorporación de la población infanto-juvenil inmigrante como fuerza de trabajo internacional, principalmente, reflexionando en torno a la necesidad de este grupo para obtener mejores condiciones de vida en medio de un contexto sustentado en el desarrollo desigual que imposibilita a los EstadosNación cumplir con los derechos propios de esta población. Para ello, se indagó el estado de satisfacción de necesidades básicas de esta población en Costa Rica; lo anterior, por medio de la consulta de los datos registrados en el $X$ Censo de Población y VI de Vivienda, 2011, en el sistema REDATAM. Se finaliza reflexionando sobre la categoría Moratoria Social y las limitaciones de esta perspectiva frente al desarrollo desigual, para que la niñez y juventud migrante trabajadora construyan proyectos de vida autónomos y emancipantes.

Palabras Clave

KEY WORDS

Niñez migrante; juventud migrante; Migrant children; migrant youth; migración internacional; necesidades international migration; unsatisfied basic básicas insatisfechas; trabajo infantil y needs; child and adolescent labor adolescente
ABSTRACT

The article problematizes about the incorporation of Children and Adolescent immigrants in the international workforce, mainly thinking about the needs of this population to obtain better life conditions amid a context based on unequal development that inhibits the States in the fulfillment of the rights of this population. To accomplish this, was made a search about the state of satisfaction of basic needs of this population in Costa Rica, using to the data recorded by $X$ Census of Population and VI of Housing , 2011, at the REDATAM system. It ends with a reflection about Social Moratorium category and the limitations that this perspective has in a context of unequal development so that children and young migrant workers may be able to build autonomous and emancipated life projects.

Colombiana. Trabajadora Social por la Universidad de Costa Rica. Labora como investigadora desde el 2010 en el Centro de Investigación en cultura y Desarrollo (CICDE) de la Universidad Estatal a Distancia y cuenta con un Diploma Superior en Estudios y Políticas de Juventud del Consejo Latinomericano de Ciencias Sociales (CLACSO).

Correo electrónico: marialexmedina@gmail.com

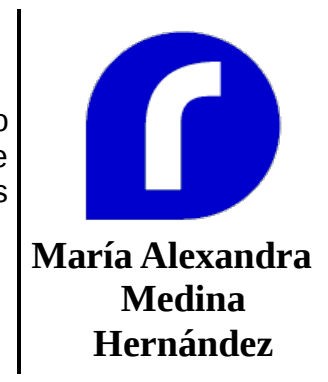




\section{Incorporación infanto-juvenil a la fuerza internacional de trabajo: el caso costarricense a partir de datos suministrados por el $X$ Censo de Población y VI de Vivienda, 2011}

\section{Presentación}

A nivel latinoamericano, el segundo patrón migratorio en importancia está dado por los movimientos poblacionales al interior de la región, lo cual ha convertido a varios países latinoamericanos en receptores de población inmigrante, tal es el caso de Costa Rica (Acuña González, 2010). Parte de la población inmigrante intrarregional está compuesta por personas menores de 18 años quienes cruzan las fronteras por diferentes causas y con distintas intenciones.

Aun cuando los estudios sobre migración internacional han progresado en la visibilización de diferentes actores involucrados en tales procesos -así como en su inclusión en estudios sobre desarrollo a partir de las remesas y el transnacionalismo- la población infanto-juvenil inmigrante sigue siendo invisibilizada como protagonista de los flujos migratorios regionales o se les percibe, únicamente, como acompañantes y en procesos de reunificación familiar, lo cual les coloca en un plano secundario, llevando a su invisibilización o a ser tomados en cuenta, tangencialmente, en los debates y políticas sobre migración y desarrollo.

Por ello, este artículo representa un aporte para visibilizar a la población infantil y juvenil; asimismo, problematiza sobre su condición —en este casocomo parte de la fuerza de trabajo internacional. Visibilizarla como protagonista de los flujos internacionales de fuerza de trabajo es un reto, pues como ya se mencionó, el debate en torno a esta cuestión social se ha centrado en las experiencias de las poblaciones adultas migrantes.

Las reflexiones expuestas en el presente documento surgen y se desarrollan en el transcurso del Diploma Superior en Estudios y Políticas de Juventud de la Red CLACSO de Posgrados en Ciencias Sociales, partiendo de los datos 
arrojados por el Censo de Población y Vivienda de Costa Rica de 2011, con la intención de evidenciar la cuestión social que aquí interesa; para ello, se realiza un acercamiento a las condiciones materiales de vida de esta población que a pesar de ser discursivamente una de las más protegidas, también suele vivir complejas condiciones de exclusión y explotación en las economías latinoamericanas. Se reflexiona sobre lo que la migración laboral implica para la población infanto-juvenil cuando, por una parte, desde el discurso de desarrollo humano se espera que construyan un proyecto de vida emancipante, pero por otra parte, las necesidades básicas están insatisfechas limitando las oportunidades de desarrollo humano.

Es de interés pensar en torno a la manera en que se construye la relación entre "población infanto-juvenil" y el "proceso de migración" comprendido como proceso social y cultural, además de económico; no obstante, esta reflexión se enfoca en pensar de qué manera la población infanto-juvenil migrante trabajadora obtiene o no las condiciones materiales necesarias para construir mejores condiciones de vida en Costa Rica, pues aun cuando los procesos migratorios podrían ser estrategias fundamentales para que esta población pueda construir un proyecto de vida — después de haber sido históricamente excluida de importantes transformaciones sociales y políticoeconómicas de la región-, las posibilidades reales de tener éxito en tal proceso dependen de varios factores que podrían ser contradictorios entre sí, como por ejemplo, la necesidad de trabajar para sobrevivir versus el acceso a derechos de educación y salud.

\section{Costa Rica, espacio de procesos migratorios}

Centroamérica se ha caracterizado por ser una región que experimenta profundas transformaciones políticas, económicas, sociales y geomorfológicas (ante desastres naturales) desde la segunda mitad del siglo $\mathrm{XX}$, e incluso a inicios del siglo $\mathrm{XXI}$; transformaciones que promueven diversos procesos de migración que, principalmente, se expresan en:

[...] tres momentos migratorios significativos en la historia centroamericana de los siglos XX y XXI: 1. La agroexportación, modernización e incipiente formación de mercados labores; 2 . Los desplazamientos forzosos durante los conflictos armados; 3. La transnacionalización laboral y la globalización en Centroamérica (Jiménez Matarrita, 2011, p. 44).

Comprendiendo que existen diversos procesos históricos que han generado profundas transformaciones estructurales en la región centroamericana, que 
a su vez promueven procesos migratorios con distintas causas e intencionalidades, en esta reflexión comprenderemos el desplazamiento migrante que históricamente se ha dado hacia Costa Rica como confluencia de dos condiciones estructurales: por una parte, se tiene la expulsión de población desatendida por los Estados-Nación en los cuales las transformaciones económicas y políticas producen exclusión y, esta población, como estrategia de sobrevivencia, busca otros Estado-Nación a los cuales integrarse, esperando así tener los medios para satisfacer sus necesidades; y, por otra parte, están los Estado-Nación como el costarricense, que promueven atracción de población inmigrante, ya que requiere de esta para mantener su economía, especialmente, para satisfacer la demanda de mano de obra no calificada y barata (identificada con sectores como agroindustria, construcción, servicios domésticos, etc.), para lo cual ha recibido migración intrarregional generando así una estructura de producción que se sustentan en el mercado dual de trabajo (Massey, Arango, Graeme, Kouaouci, Pellegrino, y Taylor, 2000).

De manera específica, Morales (2008) afirma que desde la década de 1980 - es decir, a partir de la implementación de políticas neoliberales, así como las transformaciones del modelo de producción tradicional hacia un modelo de desarrollo agroexportador - Costa Rica ha experimentado un reordenamiento económico y social que origina nuevas actividades productivas y cambios en el mercado de trabajo, situación que evidenció la carencia de mano de obra poco calificada en el mercado nacional, lo cual dio pie para estimular la contratación de inmigrantes provenientes de países vecinos $^{1}$. Es este contexto el que da espacio a la contratación de población menor de 18 años en trabajos que no requieren calificación o que se pueden realizar por temporadas.

Las condiciones precarias de vida de la población infanto-juvenil inmigrante trabajadora que se evidencian a partir de la recuperación de algunos datos del Censo 2011 se pueden leer y entender desde la noción de desarrollo desigual de la Teoría de Sistemas Mundiales explicada por Delgado Wise, Márquez Covarrubias y Rodríguez Ramírez (2009), comprendiendo así el impacto diferenciado del capitalismo transnacional contemporáneo en las condiciones de vida de la población mundial, según la cual, dependiendo de la posición que tenga uno u otro país en el ordenamiento del capitalismo transnacional se verá afectado o beneficiado por el flujo de capitales internacionales (la inversión en tierras, materias primas, nuevos mercados de consumo y mano de obra); por tanto, desde esta teoría se puede explicar que la migración económica desde países periféricos hacia países semiperiféricos o centro (como podría ser Costa Rica en Centroamérica), es el flujo de mano de obra que sigue los movimientos del capital trasnacional, todo lo cual va generando la creación de cadenas laborales trasnacionales. 
No obstante, también existe otro movimiento que ha sido evidenciado a partir de estudios fundamentados en la "segunda ola" del transnacionalismo, según la cual, el capital sigue el paso a las prácticas transnacionales de los migrantes; por consiguiente, los movimientos que realiza la población migrante impactan en el capital global, pues este busca captar tanto las remesas de esta población como la mano de obra.

Este doble movimiento se articula con las constantes estrategias de reestructuración del sistema-mundo capitalista —ante las constantes crisis que le son propias- como: la internacionalización de la producción, el comercio y división del trabajo, junto con la imposición de políticas neoliberales; las cuales, han atravesado la historia contemporánea de Costa Rica, país que promueve la inversión extranjera logrando que algunas empresas nacionales y transnacionales se articulen e instalen fábricas, agroindustrias, cadenas hoteleras, inmobiliarias (constructoras), etc., que aportan algunos empleos con salarios bajos y dinamización del consumo interno.

Según datos expuestos más adelante, por las ramas de actividad económica en las cuales se contrató a esta población para el 2011, se puede inferir que este tipo de empresas transnacionales contratan o subcontratan inmigrantes menores de edad que fueron desplazados de sus países natales - colocados como periféricos en el ordenamiento del sistema-mundo -producto del desempleo estructural y la exclusión social que amenaza su sobrevivencia, optando así por incorporase de manera precaria a las cadenas globales de producción para sobrevivir.

Ahora bien, de manera general, en relación con movimientos migratorios internacionales, Costa Rica es tanto receptor, como expulsor y de tránsito, pero al ser estudiado como receptor de población inmigrante tanto intrarregional $^{2}$ como extra-regional ${ }^{3}$ en condición temporal, estacionaria y permanente, ha primado el interés por entender-justificar a Costa Rica como país que atrae flujos migratorios por ofrecer, no solo opciones laborales, sino mejores condiciones de vida. Por medio de los datos y el análisis que se plantea en este documento, se trata de evidenciar que para la población infantil y adolescente inmigrante trabajadora estas mejoras de vida han estado en paréntesis, pues han sido expulsados de su país natal por condiciones de exclusión y violencia, para llegar a un país en el que deben ingresar al mercado laboral para poder sobrevivir y aportar a la sobrevivencia familiar. Aun cuando en Costa Rica existe una estructura institucional desde la cual se podrían garantizar sus derechos en tanto población menor de edad - partiendo del principio según el cual prima el interés superior del menor de edad-, las posibilidades de acceder a los derechos se vuelven engorrosas en tanto población menor de edad inmigrante y aún más si es indocumentada.
2. Panamá, Nicaragua, El Salvador, entre otros.

3. Colombia, Cuba, República Dominicana, Haití, China, entre otros 
Como bien lo expone Jiménez Matarrita (2011), la documentación es el mecanismo para reconocer la existencia de un ser humano y su pertenencia a una nacionalidad, por tanto, es un medio para poder disfrutar de algunos derechos y oportunidades (educación y becas, trabajo, seguridad social, asistencia sanitaria). No obstante, en procesos migratorios, especialmente de población nicaragüense -y podría ampliarse a la panameña- hacia Costa Rica, se encontró que,

[...] la falta de documentos que acredite su identidad y nacionalidad así como documento migratorio, es uno de los más graves problemas que vive la población migrante nicaragüense en Costa Rica. Buena parte de esta población carece de partida de nacimiento, pasaporte, y cédula nicaragüense. Esto genera un círculo administrativo vicioso y situaciones desventajosas que sufren de manera particular los niños, niñas y adolescentes (Jiménez Matarrita, 2011, p. 64).

Por tanto, cuando se piensa en la relación "migración - desarrollo humano derechos humanos", el alcance del principio de Universalidad de los Derechos Humanos es alterado, pues el acceso a estos queda supeditado a la condición migratoria y, por ende, las oportunidades de desarrollo humano que puedan tener las personas en procesos migratorios.

A pesar de la necesidad del mercado nacional por la mano de obra migrante no calificada, las políticas dirigidas a esta población son más regulatorias del movimiento fronterizo que de protección de derechos, es decir, durante la primera década del 2000 no hubo políticas sociales efectivas que aseguraran la calidad de vida de esta población. Aunque es una cuestión social claramente documentada desde la década de 1980, para inicios del siglo XXI aún no se había establecido una política social clara garante de derechos humanos para la población inmigrante, por el contrario las leyes y los procesos administrativos están llenos de contradicciones y vacíos.

Siguiendo lo expuesto en el Estado de la Niñez y la Adolescencia Migrante (EDNAM) (Jiménez Matarrita, 2011), entre 1995 y 2005 en Costa Rica se registró una alta tasa de recepción de inmigrantes, periodo durante el cual, progresivamente, se fue construyendo "[...] una sensibilidad temerosa y hostil que parecía responsabilizar a los inmigrantes nicaragüenses de los problemas en la institucionalidad pública y en la convivencia social costarricense" (p. 136). En relación con este punto, Brenes, Paniagua y Sandoval (2012) exponen cómo las leyes de migración y extranjería creadas en la primera década del 2000 se fundamentaron en los discursos de seguridad nacional y ciudadana lo cual llevó a que se enfocaran en la 
persecución de la migración denominada como "ilegal" y la promoción de los movimientos migratorios que se considerara contribuían al desarrollo del país, es decir, se ve la inmigración de población trabajadora como un problema o amenaza para la seguridad costarricense y la migración de inversionistas como fenómeno a ser estimulado, ya que sería este el que aportaría al desarrollo del país, más no el otro.

Aunado a este contexto legal y hostil para la inmigración trabajadora, Morales (2008) evidencia el rezago en la generación de políticas para incorporar a la población inmigrante en el sistema social a partir de su condición de población trabajadora, es decir, durante décadas no se les ha reconocido las garantías laborales-sociales correspondientes, producto de su aporte a la economía nacional.

En el caso de la población infanto-juvenil inmigrante trabajadora, lo anterior puede explicarse, a partir de varios factores entre los cuales podemos encontrar: la contratación encubierta de población inmigrante indocumentada; la ilegalidad en la que se estaría incurriendo al contratar a personas menores de 15 años (las cuales nunca serán reconocidas como trabajadoras ante el seguro social, al ser estipulado como explotación laboral infantil siguiendo el Código de la Niñez y la Adolescencia [CNA], artículo 92); y por el uso - por parte de empresas agroexportadoras- de redes de tráfico transfronterizo 0 de contratistas que ingresan a esta población en condiciones clandestinas para que no sean detectadas por la Dirección Nacional de Migración y Extranjería. Por esto, es necesario cuestionar esa premisa idealizada de Costa Rica como país paraíso para la población trabajadora inmigrante.

Ahora bien, a partir de 2010 entró a regir la Ley $n^{\circ}$ 8764, la cual en el artículo 6 inciso 7 postula que deben cumplirse los derechos de las niñas, niños y adolescentes migrantes de conformidad con las convenciones internacionales firmadas por Costa Rica, sustentándose en el interés superior del menor. Principalmente, la ley hace referencia a la responsabilidad del Patronato Nacional de la Infancia y de las autoridades migratorias en la atención de personas menores de edad que migran no acompañadas, para iniciar un proceso de protección de derechos, así como resolución de su condición migratoria, según se considere necesario para respetar su interés superior (artículo 65); no obstante, el Reglamento N³6695-G, para la aplicación de la Ley 8764, se centra en la regulación del ingreso, permanencia y egreso de personas menores de edad nacionales y extranjeras, con la intención de fomentar la integración, dejando claro que la integración está acentuada en la documentación y regularización.

Aunado a esto, en el mismo EDNAM (Jiménez Matarrita, 2011) se reconoce que para la primera década del 2000 no existe una política social migratoria que aclare el acceso de la población infanto-juvenil a derechos como salud y educación, áreas que se supone son fundamentales para la población menor 
de edad, ya que a partir de estas es que tal población puede tener acceso a los principales recursos para una óptima inclusión en sociedad. Por tanto, las expresiones de exclusión son justificadas a partir de la supuesta "ilegalidad" en la cual se encuentran niñas, niños y jóvenes que no tienen la documentación solicitada por el Estado y sus instituciones, es decir, existe la visión de que la raíz de los problemas de integración de la población infantojuvenil está dada por la indocumentación, negando así contradicciones más profundas en la estructura político-legal, así como la falta de claridad en procesos administrativos que faciliten el cumplimiento de derechos en vez de entorpecerlos.

\section{Población infanto-juvenil en cadenas regionales de migración}

Como producto de las transformaciones económicas y políticas que promueven procesos de migración, resulta necesario visibilizar la situación de diversas poblaciones que están excluidas del análisis de migración producido desde y dentro de la región centroamericana, entre ellas la población infanto-juvenil migrante la cual trabaja bajo condiciones de explotación. A nivel regional, se publicó un estudio por Acuña González (2010) para DNI-Internacional, en el cual se explica que la migración de niñez y jóvenes ha sido poco documentada en la región, pero que a partir de casos empíricos es posible constatar tanto su existencia como su aumento por la necesidad de reunión familiar o, en algunos casos, por iniciativa propia, es decir, migrando solos, según Acuña González (2010) esto es una estrategia de sobrevivencia dado el aumento de la pobreza en la región y la dificultad que tiene esta población para acceder a servicios públicos básicos dentro de sus países, de manera general, este autor trata de evidenciar que la migración como estrategia de sobrevivencia, es muestra del riesgo social en la que se encuentra la población infanto-juvenil de la región ya que, por una parte, en los países de origen no les dan respuesta a sus necesidades básicas y, por otra parte, en el proceso de migración y de inserción en el país receptor, estas cuestiones no se abordan de manera político-legal.

Como antecedente, también se tiene que la OIT publicó en 2006, como parte de su reporte anual sobre el panorama laboral mundial, un reporte especial sobre las migraciones internacionales, enfocándose en la situación de Latinoamérica y el Caribe. Si bien aún no se evidenciaba la crisis humanitaria de miles de niños, niñas y jóvenes inmigrantes centroamericanos que han intentado cruzar la frontera entre México y Estados Unidos a lo largo de la primera y segunda década de 2000, el reporte de la OIT (2006) evidenció que la población joven presentaba mayor predisposición a emigrar "[...] lo que se relaciona directamente con las dificultades que enfrentan en sus países de origen para encontrar empleo, ingresos adecuados y mejores perspectivas laborales y educativas, así como con la migración familiar" (p. 48), específicamente sobre la situación de la migración intrarregional, se 
menciona que "[...] los jóvenes han representado alrededor del $17 \%$ del total de migrantes en los últimos años, y el grueso reside en Argentina, Costa Rica y Venezuela, con preponderancia de las mujeres dedicadas a servicios domésticos" (p. 48)

Para ampliar el análisis que aportan tanto Acuña González (2010) como la OIT (2006), se cuenta con los reportes y análisis que vienen realizando diferentes organismos, autores y autoras de la región, quienes exponen que la situación de niñas, niños y jóvenes menores de 18 años que migran es de alta vulnerabilidad, pues responden a una serie de desigualdades y violencias estructurales, así como a modos de vida que se sustentan en el ciclo migratorio, modos de vida que históricamente ciertos grupos poblacionales han adquirido y empezado a mantener como respuesta al abandono estatal, para así satisfacer sus propias necesidades básicas.

Por ejemplo, Cabrera Duarte y Valdéz Gardea (2013) explican que la niñez migrante es producto de un contexto contradictorio, en el cual, por una parte, se nace y se crece teniendo la experiencia de la migración de manera cercana, ya sea porque se conoce sobre ella por medio de los diversos medios de comunicación o porque familiares y vecinos ya han emigrado, pero, por otra parte, las leyes criminalizan esos movimientos mientras avalan la libre circulación de mercancías. No obstante, Cabrera Duarte y Valdéz Gardea (2013) explican que la motivación de niñas, niños y jóvenes para migrar resulta de condiciones estructurales como exclusión social, pobreza y violencia, además, explican que a largo plazo la migración se ha convertido en un patrón cultural que las nuevas generaciones esperan repetir ya que se convierte en un medio para mantener la subsistencia, pero también para reunirse con aquellos que han emigrado, "[...] por lo que emprender el viaje que ya han hecho sus familiares o vecinos es parte de una etapa de sus vidas" (Cabrera Duarte y Valdéz Gardea, 2013, p. 351), "[...] donde los menores se convierten en herederos sociales de la realidad que han vivido los migrantes adultos." (Cabrera Duarte y Valdéz Gardea, 2013, p. 352).

Igualmente, Girón Solórzano (2014) apunta que, a raíz del aumento de migración de niñas, niños y adolescentes a través de las fronteras guatemaltecas hacia México y Estados Unidos, se ha hecho necesario colocar a esta población como actores de los procesos migratorios, pero que aún se carece de suficiente información para comprender y actuar de manera efectiva sobre estos movimientos, aun cuando son producto histórico de un comportamiento que la población joven ha ido adquiriendo desde la niñez temprana al cruzar, junto con familiares, la frontera sur de México para trabajar en agricultura.

De manera general, se rescata que Girón Solórzano (2014) expone varias motivaciones que tienen las poblaciones infanto-juveniles guatemaltecas para migrar, por ejemplo: la reunificación familiar; la situación económica (pobreza); huir de la violencia (intrafamiliar, así como la ejercida por las 
maras); el imaginario social que se tiene de la vida en Estados Unidos; y de manera particular, resulta importante la necesidad por parte de mujeres jóvenes de alejarse de una cultura opresora, ya que en entrevistas hacen referencia a que por medio de la migración podrían alejarse de una cultura que las vigila constantemente y solo las prepara para el cuido de hijos y esposos, por lo que la migración les aseguraría la oportunidad de tener un proyecto personal de vida que posibilite la autonomía y relativa independencia de sus progenitores.

De manera semejante, en relación con la situación de El Salvador, World Vision (2014) expone resultados de encuestas y entrevistas efectuadas a padres, madres, responsables de niñas, niños y jóvenes menores de 18 años que han migrado, así como de grupos focales realizados con niñas, niños y jóvenes de áreas específicas del país, todo con el fin de comprender las motivaciones que hay para que esta población realice procesos migratorios de manera acompañada y no acompañada hacia Estados Unidos, así como dentro del país. En síntesis, se puede decir que el documento apunta que los motivos varían según la edad de la persona, su relación de dependenciaindependencia económica con el núcleo familiar y su género. Por ejemplo, se obtuvo que la reunificación familiar resultó ser la motivación de más peso puesto que, como parte del ciclo migratorio, miembros de la familia nuclear ya migraron, por lo que niños, niñas y jóvenes esperan cruzar para completar el proceso; en cuanto a las motivaciones económicas, como conseguir un trabajo, se encontró que si bien no es la motivación principal para menores que son aun económicamente dependientes, ni para aquellos menores de 12 años, sí lo puede ser para los jóvenes mayores de 12 años, no obstante, de manera general, se encontró que la situación de pobreza resulta ser motivo para que todos se interesen en migrar; finalmente, se consultó por motivos relacionados a la violencia contextual del país, encontrando que las amenazas a la seguridad física así como el intento de ser reclutados en pandillas resultan ser las principales motivaciones para migrar dentro y hacia fuera del país, sin embargo, para las mujeres jóvenes el hostigamiento o persecución para ser parte de las pandillas se da con la intención de que den servicios sexuales como novias o esposas de pandilleros.

Por tanto, si bien existen otros documentos que a nivel regional están empezando a registrar la cuestión social que aquí interesa, a partir de los autores y las autoras anteriormente citados es posible vislumbrar que la migración de población menor de edad en la región centroamericana y norteamericana (México) se ha ido profundizando y es motivada por un contexto social, político y económico que les excluye y expulsa de sus comunidades, que tienen como motivación la mejora de condiciones de vida, económicas y de búsqueda de empleo, en general, así como la reunificación familiar y escapar de violencia familiar, comunitaria, estatal. 
Como explica Reguillo (2010), la migración internacional ha terminado siendo una opción para la población joven ante las contradicciones estructurales,

[...] frente a la precarización creciente, tanto económica como vital, frente a la carencia objetiva de oportunidades, frente al deterioro de la seguridad social, miles de jóvenes "deciden" migrar como una solución "individual", que se asume con recursos propios [...] que se asume como riesgo inevitable, que se vislumbra como un destino "natural" en el contexto de la propia biografía [...] (Reguillo, 2010, p. 400-401).

Cabrera Duarte y Valdéz Gardea (2013), Girón Solórzano (2014) y World Vision (2014), aportan un amplio panorama de situaciones a tomar en cuenta, entre lo que dicen estos autores y autoras, aunado a lo expuesto por Reguillo (2010), es posible visibilizar la existencia de la migración forzada por circunstancias apremiantes para sostener la vida; no se trata de migraciones por decisión individual o migraciones racionales para promover desarrollo de sus países nativos mediante remesas o emprendedurismo transnacional, sino como única alternativa ante la precarización de las condiciones de vida en sus lugares de origen, así como por la búsqueda de oportunidades para sus proyectos de vida.

A lo anteriormente expuesto, es necesario sumar el complejo contexto al cual se enfrentan las juventudes en América Latina, Valenzuela (2010) explica que:

[...] los jóvenes enfrentan escenarios difíciles que limitan sus proyectos de vida, y recurrentes procesos de criminalización social que convierten a las identidades juveniles en identidades desacreditadas que amplían sus marcos de vulnerabilidad. La crisis obnubila los horizontes juveniles junto a la atenuación de los canales tradicionales de movilidad social como el trabajo y la educación, que pierden centralidad frente a las expectativas delimitadas por el desplazamiento originado por la miseria o el miedo [...] (p. 327).

Desde lo expuesto por los anteriores autores, empezamos a vislumbrar que es en las primeras décadas del siglo XXI cuando, en los estudios sociales, este proceso se hace cada vez más notorio como estrategia de sobrevivencia entre la población infanto-juvenil centroamericana, pero al ser una estrategia 
que conlleva cuestiones sociales a ser atendidas, así como peligros, dada la clandestinidad bajo la cual opera, pasa a ser criminalizada por las autoridades y, por ende, se criminaliza a los sujetos que la utilizan.

Recordemos que en el caso de población nicaragüense y panameña, por las dinámicas fronterizas, se encuentra población que viene al país de manera indocumentada y que esta condición estuvo penada mediante la Ley $n^{\circ} 8487$, la cual se fundamentaba en el discurso de seguridad ciudadana y nacional, por lo que la indocumentación se equiparó a ilegalidad, por tanto, aportó a la criminalización de la población inmigrante trabajadora. Según Brenes, Paniagua y Sandoval (2012), especialmente la Ley $n^{\circ} 8487$, aprobada en 2005 (en vigencia hasta el 2010), "[...] parece responder a temores e imágenes estereotipadas alrededor de la inseguridad, la invasión, el desorden y la necesidad de controlar los movimientos de ciertas personas" (p. 27).

De esta forma, es posible visualizar que para el 2011 -año cuando se realiza el X Censo Nacional de Población y VI de Vivienda y del cual se toman los datos para realizar el siguiente análisis- las condiciones políticolegales que rodeaban a la población infanto-juvenil trabajadora eran desfavorecedoras, lo cual aportó a que sus condiciones materiales de vida se pauperizaran aun cuando pudieran incorporarse al mercado laboral costarricense, pues la clandestinidad e indocumentación limitaron sus oportunidades.

Siguiendo la explicación de Rodríguez (2011) sobre las paradojas que enfrentan las juventudes latinoamericanas, se tiene que una de ellas en el desarrollo desigual es que las poblaciones jóvenes son más afectadas por las migraciones inciertas, pues si bien se ha establecido que la juventud tiene la capacidad de ser flexible ante los contextos que se le presentan, las naciones a las que llegan como inmigrantes no necesariamente generan acciones para su integración y las naciones de expulsión no están generando acciones para evitar el flujo hacia el exterior, por lo que esa flexibilidad empieza a perderse en un contexto de rigidez y creciente desigualdad para poder ser y desarrollarse plenamente.

DNI (2006, citado por Acuña González, 2010, p. 17) explica que el trabajo infantil y joven migrante es una expresión de la inequidad y desigualdad existente en la región centroamericana, pues cada vez es más difícil el acceso a servicios básicos desde la perspectiva de derechos, ya que se han transformado en servicios privados; el Estado se ha retraído en su papel social; y ha aumentado el desempleo, la informalidad y el salario precario de los trabajos de la población adulta.

Esta problematización, a la cual contribuyen varios/as autores/as, es fundamental para aportar a la deconstrucción de las visiones homogenizantes y estigmatizadoras de la realidad de las poblaciones 
jóvenes de la región. Estas visiones se pueden resumir en dos —que son opuestas- en torno a los atributos otorgados a la niñez y la juventud.

Por una parte, una visión romantizada que ve a la población joven como en un periodo de moratoria, de transición, entre la niñez y la adultez, es decir, se trata de la visión romántica de la niñez y la juventud, que se sostiene sobre el discurso que se construyó para poder aumentar el tiempo de relevo laboral entre una generación y otra. Como lo explica Reguillo (2003), con el aumento de la esperanza de vida y el envejecimiento tardío, producto de la reconfiguración del mundo posguerras, se reorganizaron procesos de inserción laboral de los segmentos más jóvenes, pues era necesario restablecer la balanza de la población económicamente activa, así que la incorporación de las generaciones de relevo tenía que posponerse, lo que llevó a establecer que lo apropiado para la niñez y la juventud era ser retenidos durante periodos más largos en las instituciones educativas.

Por otra parte, está una perspectiva que coloca a la niñez y la población joven, en general, como problemática, a partir de la cual,

[...] la sociedad ha encasillado a sus jóvenes con tantos calificativos, que ha construido una serie de máscaras sobre lo que se piensa se supone que es la juventud; según estos los jóvenes son irresponsables, rebeldes, violentos, incontrolables, en una palabra, son lo instintivo, lo que está fuera de cauce [...] (Pérez Islas, 2000, p. 200).

No obstante, es necesario comprender que categorías como niñez y juventud - las cuales hacen referencia a poblaciones específicas- están vacías de contenido si se les estudia fuera de un contexto histórico y sociocultural (Valenzuela, 2009), si se les utiliza indiferentemente para hablar de uno u otro grupo de personas en diversidad de contextos, tiempos y espacios, ya que esto lleva a que sean categorías cargadas de estigmas, identidades esencialistas y homogenizadas, que niegan la diversidad e, igualmente, las desigualdades sociales, económicas, políticas y culturales que afectan a estas poblaciones.

Por tanto, como expone Reguillo (2003), se trata de preguntarse por los modos en que la población infantil y la población joven viven, experimentan e interpretan un mundo tensionado por los múltiples conflictos que este les impone, en este caso, interesa cuestionar sobre las posibilidades que tienen las poblaciones menores de edad trabajadoras migrantes de construir condiciones de vida adecuadas cuando la incorporación temprana al mercado laboral resulta indicio del deterioro de los derechos fundamentales 
de la niñez y la juventud aun cuando tales han sido establecidos y protegidos mediante leyes nacionales y convenios internacionales.

De manera contextual, se comprende que este deterioro de los derechos fundamentales de las poblaciones menores de edad está vinculado con la crisis política, social, económica que enfrenta la sociedad latinoamericana producto de las reconfiguraciones estatales con las políticas neoliberales, así como por las repercusiones que han dejado las guerras, las dictaduras, la focalización de la asistencia social, el deterioro de los derechos laborales, el capitalismo transnacional, entre otros. Es decir, los problemas que enfrenta la población infantil y adolescente que es obligada a incorporarse al mercado laboral, son problemas producto de las contradicciones que permean a todas las sociedades latinoamericanas marcadas por el deterioro de las instituciones estatales y sociales encargadas de proveer la seguridad social entendida como medio para plasmar los derechos humanos en la vida cotidiana.

\section{Caracterizando a la población infanto-juvenil inmigrante en el mercado laboral de Costa Rica a partir del X Censo de Población y VI de Vivienda -2011}

Partiendo de la notoriedad que ha tomado esta cuestión social resulta imperante conocer cuál es la situación de la población menor de edad inmigrante que ingresa al mercado laboral en Costa Rica. En el 2011 se publicó el primer Estado de la Niñez y la Adolescencia Migrante (EDNAM), (Jiménez Matarrita, 2011), el cual confirma el desconocimiento en cifras exactas de la población infantil y adolescente migrante nicaragüense que trabaja, pero reconoce tener evidencias sobre su explotación laboral y económica. En el EDNAM (Jiménez Matarrita, 2011) se identificaron tres motivos principales por los cuales la población infantil y adolescente migra hacia este país: reunificación familiar, búsqueda de opciones laborales y construcción de un proyecto de vida, información que se corresponde con las expresiones que ha adquirido esta cuestión social en el resto de la región centroamericana.

Según Jiménez Matarrita (2011), existen deficiencias en el levantamiento de información acerca del trabajo infantil y adolecente migrante por lo que no es posible caracterizarlo, pero se sabe que muchos y muchas trabajan "colaborando con sus familiares" en la industria agroexportadora, así como en el comercio informal y en Trabajo Infantil y Adolescente Doméstico (TIAD). También, se presentan casos de violencia física y emocional por parte de patronos, así como casos de explotación laboral y violación de garantías laborales, por ello resultan de interés los datos que arroja el " $X$ Censo de población y el VI de vivienda del 2011", debido a que permite dar una base 
cuantitativa a las conclusiones a las que han llegado expertos y expertas en el tema a partir de su experiencia práctica.

En el EDNAM (Jiménez Matarrita, 2011), se afirma que es posible constatar cuáles son las condiciones de vida de esta población a partir de las condiciones materiales de sus padres o encargados, no obstante es oportuno utilizar los datos ofrecidos por las encuestas y los censos para evidenciar la situación de esta población a partir de categorías que agrupen tanto su situación personal como la del hogar al que pertenece. A continuación, se describe, brevemente, la situación de esta población a partir de la información más reciente sobre la situación nacional que se desprende del " $X$ Censo Nacional de Población y VI de Vivienda 2011".

Este Censo se realizó entre los meses de mayo y junio de 2011. Si bien el Instituto Nacional de Estadística y Censos (INEC) de Costa Rica publicó un estudio específico sobre la situación de la población menor de edad que vivía en el país para el periodo mencionado, este no explicita información sobre población menor de edad migrante, sus condiciones de vida y si están o no articulados a procesos de trabajo; por lo tanto, se procedió a buscar los datos mediante el sistema REDATAM del INEC con el cual se pueden sacar frecuencias y cruces de variables de características como vivienda, hogar y población.

Ahora bien, es necesario tener en cuenta tres posibles sesgos por subregistro del proceso de este Censo:

a. Solo pregunta por la situación ocupacional de personas a partir de los 12 años de edad, siendo desconocida la situación laboral y de explotación de personas menores a tal edad.

b. La población nacida de madres extranjeras es contada como nacional; no obstante, su situación económico-social puede ser similar a la de menores trabajadores/as migrantes, pero no se tiene acceso a esta información porque han sido registrados como nacionales, no como extranjeros/as ni como hijos/as de extranjeros/as.

C. El total de 385602 personas censadas como inmigrantes, no coincide con el total registrado por la Dirección de Migración y Extranjería (DGME) para junio del 2011, pues según esta instancia estatal debían haber 364694 personas migrantes con documentos al día ${ }^{4}$ (sin contar personas en condición de refugio, según DGME que eran de 9206 en el 2012; dándonos un aproximado de 373900 personas inmigrantes en el país), por esto, se podría inferir que el $X$ Censo de población registró cerca de 11702 personas con condición migratoria incierta, dentro de estas podrían estar personas trabajadoras menores de edad; evidenciando la posible cantidad de personas sin
4. Residencia permanente, temporal y con categorías especiales. 
documentación que trabajan en el país y la posible existencia de otros/as que hayan pasado desapercibidos por el Censo de población ya que la población inmigrante en Costa Rica se caracteriza por tener un comportamiento "nómada" o transfronterizo, ya que se mueven dentro del país, o de un país a otro, según oportunidades laborales estacionarias.

Aunque hay subregistro y tomando en cuenta que ya pasaron 4 años desde la publicación de la información censal, la caracterización realizada en este documento a partir de tales datos supone dar insumos para problematizar y visibilizar las contradicciones que limitan las posibilidades de la población menor de edad inmigrante trabajadora para construir condiciones de vida dignas.

Los datos se van a presentar de la siguiente manera. Primero se abordará de manera general una caracterización de la población infanto-juvenil inmigrante trabajadora desde la incorporación a diferentes ramas de actividad económica; posteriormente, se empezará a exponer algunas categorías relacionadas con la satisfacción de necesidades básicas.

Inicialmente, es necesario tener claro, como se puede visualizar en la tabla 1, que la situación laboral de 2672 personas menores de edad migrante refiere a una situación nada insignificante (teniendo presente los subregistros), pues evidencia perfectamente la existencia de riesgo social y económico de dicha población en la región. En esta primera tabla, podemos ver que en los resultados censales, expuestos en 2011, se registraron 2050 hombres inmigrantes menores de 18 años incorporados en la fuerza de trabajo, así como 622 mujeres inmigrantes menores de 18 años en la misma situación.

Con respecto a la situación de las mujeres que trabajan en empleo doméstico remunerado (identificada bajo la clasificación "actividades de los hogares en calidad de empleadores de personal doméstico" [INEC, 2011b]) es importante recordar que en Costa Rica se tiene prohibido la contratación de personas menores de 18 años para labores que se consideran peligrosas (CNA, Art. 94; OIT, 1999a; OIT, 1999b), entre las cuales se tiene el trabajar en labores de cuido de menores, adultos mayores o personas con discapacidad, en vigilancia o en horas nocturnas (Jiménez Matarrita, 2011); a pesar de esto, muchas de las mujeres jóvenes migrantes empiezan su vida laboral en esta actividad económica.

Tabla 1

Población ocupada en Costa Rica según condición migratoria, sexo y edad. 2011

\begin{tabular}{lll}
\hline Diferenciación de Personas & Menores de edad & Total de fuerza de \\
\hline
\end{tabular}




\begin{tabular}{lcc}
\hline $\begin{array}{l}\text { incorporadas a la fuerza de } \\
\text { trabajo según origen y sexo }\end{array}$ & $\begin{array}{c}\text { trabajadores/as } \\
(\mathbf{1 2 - 1 7} \text { años) }\end{array}$ & $\begin{array}{c}\text { trabajo en Costa } \\
\text { Rica } \\
\text { (12 años en } \\
\text { adelante) }\end{array}$ \\
\hline $\begin{array}{l}\text { Total de población trabajadora } \\
\text { en Costa Rica }\end{array}$ & 21,546 & $1^{\prime} 468,663$ \\
\hline Población costarricense & 18,874 & $1 ' 263,050$ \\
\hline Personas inmigrantes & 2,672 & 205,612 \\
\hline $\begin{array}{l}\text { Personas inmigrantes } \\
\text { mujeres }\end{array}$ & 622 & 74,658 \\
\hline Personas inmigrantes & 2,050 & 130,954 \\
\hline Hombres
\end{tabular}

Elaboración propia a partir de datos del X Censo Nacional de Población y VI de Vivienda 2011, Costa Rica

Otros datos de interés recuperados mediante el Censo (INEC, 2011a) permiten evidenciar 307 casos de personas entre 12 y 17 años que se encontraban desocupadas en el momento de la encuesta, es decir, que en algún momento estuvieron buscando empleo pero no lo encontraron, probando que existe interés y necesidad de ingresar al mercado laboral por parte de la población infanto-juvenil inmigrante.

Tabla 2

Población infantil y adolescente migrante trabajadora por las principales rama de actividad económica y sexo, 2011*

\begin{tabular}{lccc}
\hline \multirow{2}{*}{ Rama de Actividad Económica } & \multicolumn{2}{c}{ Sexo } \\
\cline { 2 - 4 } & Hombre & Mujer & Total \\
\hline Agricultura, ganadería, silvicultura y pesca & 1019 & 69 & 1,088 \\
\hline Minas y canteras & - & 2 & 2 \\
\hline Industrias manufactureras & 201 & 47 & 248 \\
\hline Suministro electricidad y gas & 6 & 2 & 8 \\
\hline Suministro agua, evacu. resid., gestión desech & 16 & 1 & 17 \\
\hline Construcción & 231 & 8 & 239 \\
\hline Comerc por mayor y menor, repar vehíc autom y & 295 & 112 & 407 \\
motoc & 34 & 5 & 39 \\
\hline Transporte y almacenamiento & 65 & 84 & 149 \\
\hline Alojamiento y servicios de comida & 7 & 1 & 8 \\
\hline Información y comunicación & 3 & 5 & 8 \\
\hline Actividades financieras y de seguros & 7 & - & 7 \\
\hline Actividades inmobiliarias & 3 & 4 & 7 \\
\hline Actividades profesionales, científicas y técnicas & 67 & 20 & 87 \\
\hline Actividades administrativas y servicios de apoyo & 3 & 11 & 14 \\
\hline Enseñanza & &
\end{tabular}


5. Otros países: Argentina (1); Canadá (3); Taiwán (2); Cuba (3); República Dominicana (1); El Salvador (17); Guatemala (3); Honduras (9); Aruba (1) Perú (1); Puerto Rico (1); Uruguay (1); Venezuela (6).

\begin{tabular}{lccc}
\hline Activ atención salud humana y asistencia social & 1 & 22 & 23 \\
\hline Activ artísticas de entretenimiento y recreativas & 23 & 6 & 29 \\
\hline Otras actividades de servicio & 29 & 21 & 50 \\
\hline Activ de los hogares en calidad de empleadores & 40 & 202 & 242 \\
\hline Total & 2050 & 622 & 2,672 \\
\hline
\end{tabular}

Elaboración propia a partir de datos del X Censo Nacional de Población y VI de Vivienda 2011, Costa Rica.

Además, en cuanto al lugar de trabajo predomina, para hombres y mujeres, ser empleados/as de empresas privadas: en total 1796; de los cuales 1498 son hombres y 298 son mujeres. En el caso específico de las mujeres, es significativo el empleo de 202 en casas particulares. Dentro de las categorías ocupacionales, es necesario señalar que 130 personas son empleadas como ayudantes sin pago (93 hombres y 37 mujeres) por lo cual se puede pensar que trabajan "colaborando" con algún familiar, lo cual, se correlaciona con los casos mencionados por el EDNAM (Jiménez Matarrita, 2011), pero como el Censo (INEC, 2011a) no nos permite obtener información sobre los ingresos, ni en estos casos de "colaboración" a un familiar ni en otras categorías con patronos, no podemos comprobar si se da una explotación laboral encubierta bajo ese eufemismo de "ayudante".

En cuanto al nivel de calificación de las labores efectuadas, se encontró que 1721 se dedican a ocupaciones elementales (no calificadas), mientras que en producción artesanal calificada se encuentran 260, en actividades agrícolas calificadas se hallaron 112 y en nivel técnico o profesional medio 37 personas.

En relación con las nacionalidades de la población migrante menor de edad incorporada en la fuerza de trabajo en Costa Rica, se descubrió gran variedad de países, predominando los siguientes: Nicaragua (2386); Panamá (85); China (41); Colombia (34); Estados Unidos (31) ${ }^{5}$; además se encontró que hay población indígena inmigrante (116) por lo cual se califica a Costa Rica como país receptor de población inmigrante regional y transregional, pero es clara la preeminencia intrarregional a partir de la cantidad de población nicaragüense y panameña.

\section{Necesidades básicas insatisfechas}

A partir del marco dado por los anteriores datos en los cuales constatamos la presencia de población infanto-juvenil inmigrante incorporada en diversidad de sectores laborales e, igualmente, entendiendo que esta incorporación temprana al mercado laboral es una irregularidad a los derechos humanos, que responde a carencias materiales, surge la pregunta: ¿cómo conocer sobre estas condiciones?;entonces, para contestarla se hará uso de las 
variables censales que se acercan a la medición de las necesidades básicas insatisfechas.

Según Méndez y Trejos (s.f.), el índice de Necesidad Básicas Insatisfechas utilizado en la metodología censal de Costa Rica consiste en hacer una caracterización de la situación en la que viven los hogares carenciados a partir de cuatro dimensiones: 1) el acceso a albergue digno, es decir, protección ante el medio ambiente (la calidad de la vivienda, el hacinamiento y alumbrado eléctrico); 2) el acceso a vida saludable, eso se refiere a viviendas con condiciones adecuadas para que los miembros puedan crecer en un ambiente sano (abastecimiento de agua de buena calidad y la eliminación de excretas); 3) acceso al conocimiento, es decir, el recurso para poder integrarse al mercado laboral y la vida social (la asistencia escolar y el rezago escolar de población entre 7 y 17 años); 4) acceso a otros bienes y servicios, se trata de la capacidad económica para satisfacer otras necesidades no contempladas en el Censo (cantidad de perceptores de ingresos y los años promedio en educación).

En la tabla 3, se puede ver que en la población menor de edad inmigrante trabajadora, prevalece una situación de insatisfacción de Necesidades Básicas, lo cual da sustento al posible motivo de su inserción laboral; la necesidad de aportar al ingreso familiar; igualmente, hay población menor de edad con necesidades básicas satisfechas incorporadas en el mercado laboral, probablemente, con su ingreso aportan a mantener las condiciones materiales de vida en el hogar.

Tabla 3

\section{Personas menor de edad según satisfacción de necesidades básicas, Costa Rica. 2011}

\begin{tabular}{lcc}
\hline \multicolumn{1}{c}{$\begin{array}{c}\text { Población menor de edad en } \\
\text { Costa Rica }\end{array}$} & \multicolumn{2}{c}{ Necesidades Básicas Insatisfechas } \\
\cline { 2 - 3 } & Sí & No \\
\hline $\begin{array}{l}\text { Total en Costa Rica (nativa e } \\
\text { inmigrante) }\end{array}$ & 468186 & 839483 \\
\hline Población nativa & 437,035 & 815,864 \\
\hline Población inmigrantes & 31,151 & 23,619 \\
\hline Población inmigrantes & 2,449 & 177 \\
trabajadora* & 1,931 & 98 \\
\hline Varones inmigrantes trabajadores* & 518 & 79 \\
\hline Mujeres inmigrantes trabajadoras* &
\end{tabular}

* La población inmigrante trabajadora corresponde a las edades entre 12 y 17 años.

Elaboración propia a partir de datos del X Censo Nacional de Población y VI de Vivienda 2011, Costa Rica. 
Además, la tabla 3 muestra que se registró un total de 31151 personas inmigrantes menores de edad con Necesidades Básicas Insatisfechas, es decir, individuos que por el riesgo social en el que se encuentran, potencialmente, podrían interesarse en ingresar al mercado de trabajo.

Si bien, a partir de la información anteriormente presentada se pueden inferir la correlación entre NBI y la incorporación al mercado de trabajo como una estrategia de sobrevivencia de la población infanto-juvenil inmigrante, es pertinente exponer otros datos que permiten comprender mejor tres dimensiones — de las cuatro- que se utilizan para medir las NBI: vivienda, salud y educación; lo anterior, para conocer un poco más sobre cómo se expresa esta insatisfacción de necesidades básicas y ampliar nuestra comprensión de las variables que entran a "moldear" las posibilidades de desarrollo humano de esta población, así como la forma en la cual el acceso a los Derechos Humanos de la niñez y la adolescencia está siendo violentado.

\section{Vivienda}

De acuerdo con la metodología expuesta anteriormente, en relación con las $\mathrm{NBI}$, la vivienda se mide por calidad, servicios públicos y hacinamiento. La mala calidad de una vivienda hace referencia a la construcción de la misma con materiales de desecho o malas condiciones infraestructurales. A partir de la consulta a los datos proporcionados por el " $X$ Censo Nacional de Población y VI de Vivienda 2011" se encontró que la vivienda de 618 personas menores de edad inmigrantes trabajadoras se califica como mala; en cuanto al hacinamiento, se halló que 831 menores viven en esta condición, de los cuales solo 173 viven en viviendas con buenas condiciones a pesar del hacinamiento.

En cuanto a la tenencia de vivienda, se descubrió que 1958 no viven en un lugar propio:

a. Población con vivienda propia: 576

b. Población pagando vivienda a plazos: 88

C. Población con vivienda alquilada: 1080

d. Población con vivienda prestada por motivos de trabajo: 560

e. Población con vivienda prestada por otro motivo:160

f. Población en precario: 158

g. Otro: 4 
Además, se encontró que 1364 viven en cuarterías, tugurios, casas móviles, camiones, baches (casa para trabajadores y trabajadoras en el lugar de trabajo).De manera general, es posible advertir precarización en la vivienda de la población menor de edad migrante trabajadora, lo cual evidencia la vulnerabilidad en dos de las condiciones materiales necesarias (acceso a albergue digno y acceso a vida saludable) para tener una vida con necesidades básicas satisfechas, pues se ven comprometidas áreas existenciales y áreas axiológicas de las necesidades básicas, como las posibilidad de ser-tener-estar en un espacio que dé protección, libertad, posibilidades para la recreación, condiciones de vida saludables, entre otros.

\section{Salud}

A partir del Código de la Niñez y la Adolescencia, en Costa Rica, toda persona menor de edad tiene derecho a la salud por medio de la seguridad social sin importar su estatus migratorio o si cotiza o no al sistema de seguridad social. No obstante, en este caso, es importante explicitar si existe o no existe un aseguramiento en el sistema de seguridad social y qué tipo de aseguramiento prevalece, pues si partimos del hecho de que esta población se encuentra en condición de asalariada, el aseguramiento por patrono es obligatorio, es decir, es un derecho laboral, debido a que además de asegurar acceso a servicios de salud, garantiza cuotas para pensión y seguridad ante riesgos laborales.

Como se pude ver en la tabla 4, más de la mitad de la población menor de edad migrante trabajadora se encontraba sin seguridad social, por lo que se evidencia la violación de uno de los derechos laborales que demuestra la pauperización de las condiciones laborales en las cuales se incorpora esta población.

Tabla 4

Personas menor de edad según seguridad social y carencias en salud, Costa Rica. 2011

\begin{tabular}{lcccccc}
\hline $\begin{array}{l}\text { Población 12-17 } \\
\text { años }\end{array}$ & \multicolumn{2}{c}{ Seguridad Social } & \multicolumn{2}{c}{$\begin{array}{c}\text { Carencias en } \\
\text { salud }\end{array}$} & \multicolumn{2}{c}{$\begin{array}{c}\text { Carencias de } \\
\text { salud y } \\
\text { seguridad social }\end{array}$} \\
\cline { 2 - 7 } & Si & No & Sí & No & Sí & No \\
\hline $\begin{array}{l}\text { Inmigrante } \\
\text { trabajador }\end{array}$ & 1090 & 1582 & 462 & 2164 & 153 & 309 \\
\hline $\begin{array}{l}\text { Varón inmigrante } \\
\text { trabajador }\end{array}$ & 778 & 1170 & 388 & 1641 & 118 & 231 \\
\hline $\begin{array}{l}\text { Mujer inmigrante } \\
\text { trabajadora }\end{array}$ & 291 & 317 & 74 & 523 & 27 & 45 \\
\hline Indígena Varón & 19 & 83 & 39 & 62 & 8 & 31 \\
\hline
\end{tabular}




\begin{tabular}{lllllll}
\hline $\begin{array}{l}\text { inmigrante } \\
\text { trabajador }\end{array}$ & & & & & \\
\hline $\begin{array}{l}\text { Indígena Mujer } \\
\text { inmigrante } \\
\text { trabajadora }\end{array}$ & 2 & 12 & 2 & 12 & - & 2 \\
\hline
\end{tabular}

* La población inmigrante trabajadora corresponde a las edades entre 12 y 17 años Elaboración propia a partir de datos del X Censo Nacional de Población y VI de Vivienda 2011, Costa Rica.

Aunado a este aspecto, desde el 2010 empezó a regir la Ley de Migración y Extranjería $N^{\circ}$ 8764, según la cual es necesario que cada persona nacida en el extranjero esté afiliada al sistema de seguridad social para poder obtener la residencia legal en el país, lo cual, como explican Brenes, Paniagua y Sandoval (2012) ha tenido como consecuencia que la responsabilidad del pago de las cuotas recaiga en la población inmigrante trabajadora, especialmente, quienes trabajan de manera informal o en empleos de temporadas y, al ser la documentación el principal medio para la integración formal de la población inmigrante, el pago de la seguridad social, más los trámites de cedulación, se convierten en una carga económica que no necesariamente toda la población inmigrante trabajadora (y familiares) pueden pagar.

Comprendiendo la ilegalidad de la contratación de las 430 personas entre 12 y 14 años que recuperó el Censo, resulta de interés ver que 232 tienen un seguro, pero de estas, 223 son por aseguramiento familiar, no por patrono. En cuanto a las 2242 personas entre 15 y 17 años se encuentra que 858 tienen un seguro, pero 427 son por aseguramiento familiar y 278 por un patrono.

Se evidencia así que los patronos no quieren asumir su responsabilidad en relación con la salud y las consecuencias que las condiciones laborales en actividades vinculadas al agro, comercio, manufactura, trabajo doméstico pueden traer al bienestar físico de las personas menores de edad que en ellas laboran. El hecho de no asumir responsabilidad puede darse porque hay subcontratistas de por medio que solo pagan a los niños, niñas y adolescentes la jornada laboral sin hacer reconocimiento de seguridad social; también puede darse porque los patronos aprovechan la criminalización de la migración para abaratar salarios y mantener en amenaza de deportación a la población trabajadora inmigrante; entre otros posibles factores.

Es necesario evidenciar que la no cotización por parte del patrono implica, además, que este se queda con una mayor ganancia económica al no realizar los pagos que le corresponden para la seguridad social de sus empleados/as, por tanto, se constata una situación de explotación laboral a esta población. 
De esta manera, se ve cómo se ha vulnerado otro de los dispositivos sociales que posibilitaría el que esta población construya mejores condiciones de vida, pues el acceso a vida saludable se dificulta aún más a partir de la explotación laboral que esta población vive, puesto que está en una situación de desprotección que puede acarrear peores condiciones de vida, por ejemplo, ante un posible accidente laboral por no contar con seguridad social.

Es importante aclarar que ante situaciones de enfermedades o accidentes causados por condiciones laborales, si no hay registro de pagos por parte del patrono, es posible obtener un seguro por el estado, pero para esto, la Comisión Calificadora de la Caja Costarricense de Seguro Social debe realizar un estudio y evaluar la condición de pobreza; no obstante, esto no debería ser justificante para que los patronos no asuman su responsabilidad ante la seguridad social de esta población.

A partir de la tabla 4, es posible observar que por el rango de edad de la población, no es un grupo en el que se espere un alto índice de carencias en la salud, pero hay que tomar en cuenta que se registraron 462 casos con carencias de salud, de los cuales solo 153 tenían seguridad social, dejando sin cotización a 309 .

\section{Educación}

Recordando, por una parte, que discursivamente se hace referencia a la educación como la fuente o el medio por el cual la población puede tener acceso a mejores oportunidades laborales, para así mejorar sus condiciones de vida, y, por otra parte, la forma como esta se usa para dar valor a la niñez y la juventud como periodo de moratoria, la relación entre educación y trabajo infanto-juvenil resulta fundamental, especialmente, por la alta probabilidad de exclusión escolar dadas las condiciones que conlleva la temprana inserción en el mercado laboral, como: el choque de horarios, el agotamiento físicomental para mantener ambos procesos, así como las transformaciones expuestas por Valenzuela (2009): "La educación ha perdido fuerza en el imaginario juvenil como elemento de movilidad social, al mismo tiempo se presenta una fuerte disociación entre la educación escolarizada y las oportunidades laborales" (p. 31); por tanto, resulta relevante develar hasta qué grado es posible que la población inmigrante menor de edad trabajadora haya tenido que abandonar (o del todo nunca ingresar) el sistema educativo para poder incorporarse al mercado de trabajo y obtener un ingreso para aportar a satisfacer las necesidades básicas de su hogar.

Al indagar por la situación educativa de la población, se profundizó en la búsqueda y se incorporaron otros grupos de edad, pues tomando en cuenta que en materia laboral el Censo solo recupera información desde los 12 
años, pero en el área de educación obtiene información desde los 0 años de edad, esta categoría y sus variables, nos pueden ampliar el panorama al realizar tres interrogantes:

1. ¿Cuál es la situación de personas migrantes entre 0-5 años, están o no en centros de cuido?, se encontró que 2635 asisten a centros de cuido, mientras que hay 5653 que no asisten, por lo cual surgen las interrogantes: ¿de qué manera se atienden las necesidades de esta población, se quedan en casa o acompañan a sus familiares a lugares laborales?, ¿cuál será la estrategia de cuido de la población migrante en el país?, desafortunadamente, no se tienen los datos para tratar de responder a estas preguntas, pero queda abierta la necesidad de indagar al respecto.

2. ¿Cuántas personas migrantes entre 6-11 años asisten y cuántas no?, ya que existe un sesgo en la recuperación de datos del Censo porque no se pregunta si esta población realiza algún trabajo remunerado o no remunerado, interesa saber la cantidad de inasistencia. Se encontró que había 1552 que no asistían, si estos niños y niñas no asistían a clases ¿podrían ser considerados "ninis"?, o existe la posibilidad de que se dediquen a colaborar a familiares como dice la EDNAM (Jiménez Matarrita, 2011), por ejemplo, ¿podría pensarse que acompañan a sus padres y madres en procesos de migración temporal y por esto no ingresan al sistema educativo?, o por el contrario ¿será que no cumplen con los requisitos de documentación solicitados por el Ministerio de Educación Pública para poder cursar el año lectivo? Igualmente, son preguntas que evidencian la necesidad de indagar la situación laboral y educativa de esta población.

3. ¿Las personas migrantes entre $12-17$ años, recuperadas como trabajadoras, asisten o no a centros de enseñanza además de trabajar?

4. Del total de 430 niños y niñas trabajadores/as, entre los 12 y 14 años, asisten 60 y no asisten 370 .

5. Del total de 2242 adolescentes trabajadores/as, entre los 15-17 años, asisten 432 y no asisten 1810.

6. Del total de migrantes indígenas entre 12-17 años que trabajan, 12 asisten a centros de enseñanza ( 3 mujeres y 9 hombres); mientas que 104 no lo hacen (11 mujeres y 102 hombres). 
Del total de personas inmigrantes trabajadoras entre 12-17 años, quienes dijeron no asistir a un centro educativo, se tiene que hay 460 mujeres y 1720 hombres en condición de exclusión escolar. Las ramas de actividad laboral que predominan —en orden de relevancia - entre las mujeres que dijeron no asistir se encuentran: actividades de hogar en calidad de empleador; comercio; agricultura, ganadería, silvicultura y pesca; alojamiento y servicios de comida; industria manufacturera.

Mientras que las ramas de actividad laboral que predomina -en orden de relevancia - entre los hombres que no asisten a centros de enseñanza se encuentran: agricultura, ganadería, silvicultura y pesca; comercio; construcción; industria manufacturera.

Ahora bien, al averiguar si saben leer o escribir, del total de 2672, se encontró que 2558 sí saben, mientas que 114 no saben y de estas 113 no asisten a enseñanza. Por lo cual, se pude inferir que quienes saben leer y escribir tienen, al menos, algún grado de instrucción en primaria, pero probablemente tuvieron que abandonar el sistema de educación para poder migrar e insertarse en el mercado de trabajo.

Dice Reguillo (2003):

La incapacidad del sistema educativo del Estado para ofrecer y garantizar educación para todos, el crecimiento del desempleo y de la sobrevivencia a través de la economía informal, indica que el marco que sirvió como delimitación para el mundo juvenil a través de la pertenencia a las instituciones educativas y a la incorporación tardía a la población económicamente activa está en crisis (p. 359360).

La crisis del acceso universal a la educación es palpable en las condiciones de vida de la población que aquí interesa, la crisis en el acceso al conocimiento es producto de una serie de factores (como la exclusión social, la rigidez de procesos administrativos para la matrícula y aprobación de cursos lectivos, el constante movimiento de los núcleos familiares en busca de oportunidades laborales, entre otros) que promueven la exclusión escolar y, progresivamente, aumenta la necesidad de esta población de ingresar al mercado laboral. Siguiendo el cuestionamiento a la idea de "juventud como periodo de moratoria", la exclusión del sistema educativo, del espacio para acceder a conocimientos varios, es la vulneración del principal medio por el cual se esperaría que la población infanto-juvenil migrante lograra obtener mejores y mayores oportunidades en el país de acogida, para así mejorar su proyecto de vida. 
6. Como parte de las opciones registradas, se encontró que la jefatura estaba a cargo de: un suegro o suegra; abuelo o abuela; hermano o hermana; un cuñado o cuñada.

\section{Familias transnacionales}

Otro elemento de relevancia en los procesos migratorios son las redes a las cuales tienen acceso las personas migrantes, usualmente estudiadas a partir de las reconfiguraciones familiares que surgen del proceso migratorio, por esto, en cuanto a la composición familiar se indagó la relación del estado civil, la posibilidad de miembros del hogar en otro país y la relación de parentesco con la jefatura del hogar.

- En cuanto al estado civil se obtuvo que hay 2265 solteros/as; no obstante, llama la atención que para el 2011 había 381 menores de edad migrantes trabajadores en unión libre o casados.

- En cuanto a los miembros del hogar que se encuentran viviendo en otro país, se encontró que la población que tiene de 1 a 4 miembros del hogar viviendo en otro país es de 170 , mientras la cantidad de personas que tienen entre 5 y 8 miembros del hogar viviendo en otro país es de 9. Por tanto, pareciera que la población menor de edad migrante trabajadora, mayoritariamente, viven con sus familiares en Costa Rica o, en el momento del censo, habían cruzado las fronteras como migrantes temporales.

- En cuanto a la relación de parentesco con la jefatura del hogar en el que vive, se encuentra un dato muy importante, pues de los 2672 niños, niñas y adolescentes trabajadores/as hay 214 en posición de jefatura (187 hombres y 27 mujeres); mientras que 1664 son hijos/as o hijastros/as de quien ejerce la jefatura familiar. Se encuentra que 327 viven en hogares extensos ya que la jefatura la ejerce otro pariente ${ }^{6}$.

La diversidad de configuraciones familiares evidencia que los procesos migratorios no solo reunifican familias nucleares, demuestra que si la población infantil y adolescente migrante está inserta en el mercado laboral aun viviendo en una familia extensa (con varios posibles trabajadores/as) es porque las condiciones de vida de la familia no permiten la satisfacción de necesidades de todos sus integrantes. También, llama la atención la existencia 214 personas jefas de hogar, así como las 381 en unión libre o casadas, pues significa que estas deben asumir los gastos de su sobrevivencia y de posibles hijos e hijas.

Para profundizar un poco más al respecto, se efectuó una búsqueda en relación con la cantidad de menores de edad migrantes trabajadoras que en el Censo son reportadas como madres, con lo cual se encontró que hay 96 madres, de las cuales una es registrada como indígena. Estas mujeres trabajan, principalmente, en empleo doméstico remunerado (identificada bajo la clasificación "actividades de los hogares en calidad de empleadores de 
personal doméstico" [INEC, 2011b]) (36); alojamiento y servicios de comida (17); comercio (14); industria manufacturera (10). Por lo anterior, se presume que varias deberían estar aseguradas por el patrono, pero se encontró que solo 56 están aseguradas (26 por familia, 19 por patrono, 7 por Estado y 4 por cuenta propia), parece que la falta de seguro para las demás 40 mujeres se debe a que trabajan en sectores altamente informales como en puestos de comida, servicio doméstico y comercio.

Dada la informalidad laboral de varias mujeres jóvenes inmigrantes, la condición de posibles jefas de hogar, y de su situación de maternidad, conocer si satisfacen sus necesidades básicas es fundamental porque los ingresos y condiciones de vida pueden ser insuficientes para ellas ( $y$ probablemente para sus hijos/as), así, de las 96 madres, 87 de las mujeres viven con NBI, solo 14 asisten a centros de enseñanza; en cuanto al estado conyugal 35 están en unión libre, 11 casadas, 5 separadas y 45 son solteras.

Aquí es posible hacer una pequeña diferenciación por género en cuanto a las condiciones que permiten la construcción de un proyecto de vida a las mujeres menores de edad migrantes trabajadoras, pues entran en juego otras variables, como se ha evidenciado, la posibilidad de ser madre y de tener que asumir el proceso de crianza por su cuenta.

\section{Remesas}

A partir de la diversidad de configuraciones familiares, también resultó de interés escudriñar si las remesas (como bienes o dineros) son parte de las estrategias de sobrevivencia de los hogares a los cuales pertenecen estos niños, niñas y adolescentes o si no son parte de la dinámica económica de la misma, pues las remesas son elemento fundamental en los estudios sobre migración, pero en este caso aporta a visibilizar otros elementos.

De manera puntal se encontró que del total de población (2672):

- Hay 727 personas menores de edad migrantes trabajadoras que viven en hogares que envían remesas (209 mujeres y 518 hombres), de estas hay 667 personas que viven con NBI.

- En cuanto a la posibilidad de recibir remesas, se encuentra que hay 95 hogares, en los que viven personas menores de edad trabajadoras migrantes, en los cuales se reciben remesas (37 son mujeres y 58 son hombres). De esta población, se encuentra que hay 71 hogares que viven con NBI. Mientras que hay 24 hogares que reciben remesas pero viven sin NBI. 
- Al realizar el cruce entre hogares que envían y reciben dinero o bienes se encontró que hay 45 que realizan este doble trámite, de los cuales 36 viven con NBI y 9 sin NBI. Resulta interesante el envío y la recepción de bienes y/o dinero dentro de un mismo hogar, lo cual hace pensar si son transacciones binacionales o si involucran más naciones.

Dentro del debate teórico y político entorno a la relación migración internacional y Desarrollo, existen corrientes que realizan una abstracción del contexto de reestructuración económica y precarización laboral producto de la globalización neoliberal —que se alimenta de la dinámica migratoria contemporánea- y afirman que la migración contribuye al desarrollo de los países de origen mediante las remesas que estas poblaciones realizan, si bien las remesas resultan de interés para comprender el comportamiento de las migraciones internacionales, es necesario aclarar que estas han sido manipuladas por discursos desarrollistas de entes internacionales para justificar y sustentar la deuda externa de algunos países periféricos, ya que se dice que las remesas bien administradas por los Estados pueden ser fuente de desarrollo para los países "subdesarrollados".

No obstante, siguiendo la argumentación de Delgado Wise, Márquez Covarrubias, Rodríguez Ramírez (2009), es posible debatir esta propuesta pues, por una parte, se debe partir del hecho de que es el desarrollo desigual (la explotación económica, social, de recursos naturales) el que impacta a los países de las periferias generando empobrecimiento de las poblaciones de estos países, lo que lleva a que esta población genere estrategias de sobrevivencia como la emigración, que al final es exportación de la fuerza de trabajo, así las remesas en realidad son transferencias de una fracción del salario para satisfacer necesidades, consumo, emergencias, reproducción de usos y costumbres familiares, son una estrategia de sobrevivencia de las familias transnacionales.

Al realizarse este fraccionamiento del ingreso familiar, es necesario sostener los gastos de dos hogares, lo cual aumenta la carga en quien trabaja para enviar remesas y le reduce a esta la posibilidad de satisfacer sus propias necesidades de manera cómoda. Del total de población (2672), menos de un tercio viven en hogares que envíen remesas, y muchos de estos hogares viven con $\mathrm{NBI}$, por lo que es injustificado pensar que estas son la herramienta/medios para promover el desarrollo de los países expulsores de estos migrantes.

Hasta este punto, los datos anteriormente expuestos, revelan una compleja gama de situaciones que vive la población menor de edad migrante. Complejidad que devela la disparidad entre la intención por la cual migraron - construir un proyecto de vida, mejorar sus condiciones materiales de vida- y las oportunidades que la sociedad costarricense les ofrece para 
poder concretar tal intención, por lo que incorporarse en el mercado laboral pasa a ser el medio para satisfacer necesidades básicas de vida y procurar el logro de algunas metas.

Dentro de la pluralidad de situaciones en las cuales se encuentra esta población, es posible divisar que hay proyectos de vida afectados por la deserción escolar y exclusión escolar, la paternidad y maternidad a edad temprana, la unión libre y el matrimonio, todo lo cual, les lleva a tener que asumir su propia sobrevivencia y la de otros (esposa/o, pareja, hijos, hijas). Además, los proyectos de vida de todos y todas incluyen aportar al sostenimiento de la vida de sus hogares, lo cual devela que para ellos y ellas no existe la juventud como moratoria.

Aunque aquí solo se han expuesto algunos datos sobre algunas condiciones materiales de la niñez y juventud migrantes (NBI, empleo, salud, educación) $y$, de manera específica, se ha ido evidenciando la situación del segmento de la población que se dedica a trabajar, se constata que existen carencias dadas por la negación y violación de Derechos Humanos a este grupo social lo que limita su desarrollo humano, pues es necesario recordar que en el sistema capitalista, neoliberal, patriarcal y colonialista, se vive a partir de las condiciones que genera el desarrollo desigual, el mismo que les ha expulsado (junto con sus familias) de sus territorios de origen y en muchas ocasiones les sigue excluyendo dentro de las naciones receptoras que no generan respuestas integrales para que puedan tener calidad de vida y, al mismo tiempo, la oportunidad de construir proyectos de vida en condiciones equitativas.

\section{Reflexiones en torno a las consecuencias del desarrollo desigual y la migración laboral en la construcción de proyectos de vida de la niñez y juventud migrante}

Reguillo (2003) explica que históricamente se han dado tres procesos mediante los cuales la población joven se vuelve visible ante las instituciones sociales y ante las ciencias sociales: "a) la reorganización económica por la vía del aceleramiento industrial, científico y técnico que implicó ajustes en la organización productiva de la sociedad; b) la oferta y el consumo, y c) el discurso jurídico" (Reguillo, 2003, p. 359); lo anterior, nos permite pensar en procesos dinámicos de visibilización e invisibilización dentro de los cuales se enmarca la vida de la población infanto-juvenil inmigrante trabajadora.

El primer proceso, que hace alusión a la reorganización social para la producción como estrategia para manejar la cantidad de mano de obra desempleada y empleada en la modernidad, llevó a establecer como norma el posponer la incorporación de la población joven en el mercado laboral y prolongar el periodo de estudio, norma que supone vendría a ampliar las 
oportunidades para mejorar las condiciones de vida de tal población, pero se redujo a privilegio de un segmento de la población, pues el acceso al sistema educativo no ha sido posible de manera equitativa dado que los Estados y las sociedades no han podido garantizar condiciones de vida óptimas para todos y todas; factores como el desempleo, el trabajo informal, la transformación de los derechos en servicios privatizados, entre otros, expulsan a grandes grupos poblacionales de los espacios que son necesarios para mejorar sus condiciones de vida, como lo es la educación y los sistemas de seguridad social.

En relación con el segundo proceso que hace referencia a la juventud como una población que tiene espacio para el ocio y que se diferencia por el consumo cultural, es necesario recordar que existe un empobrecimiento estructural, un desarrollo desigual, dentro del cual, niños, niñas y adolescentes recurren al mercado laboral internacional para poder palear esta precariedad. Por tanto, se trata de una población que al vivir con NBI tiene limitada la satisfacción de necesidades existenciales y axiológicas como el tener espacio para participar en diferentes agrupaciones, contar con espacio de ocio, de creatividad, de recreación, de la misma manera en que lo puede hacer un niño, niña o adolescente a quien sí se le haya avalado su derecho a vivir su juventud como periodo de moratoria.

En tercer lugar, en cuanto al discurso jurídico — que se ha usado para hacer a la población infantil y joven sujetas de derechos y deberes-se reconocen una serie de necesidades, oportunidades, satisfactores, requeridos por esta población para vivir dignamente; sin embargo, no existe un contexto económico, político, social que respalde suficientemente este discurso jurídico, pues la población infanto-juvenil no vive aislada de las contradicciones socio-económicas y políticas que vive una sociedad. De esta forma, la pobreza y la violencia que les empuja a emigrar y a incorporarse a la fuerza de trabajo, evidencia que el discurso jurídico, protector y garante de derechos de la niñez y la adolescencia tiene vacíos cuando se trata de poblaciones altamente excluidas como la que hemos abordado en este análisis. En el caso de los datos que aquí se abordan, del contexto dado por la primera década de 2000 , interesa recordar que no existía una política social migratoria que evidenciara las particularidades de la cuestión social vividas por la población menor de edad migrante y que de alguna manera estableciera qué hacer al respecto.

En resumen, los procesos mediante los cuales se hace visible a la población joven son procesos que hablan de un contexto social y político-económico que idealmente debe dar las oportunidades para que todos y todas puedan construir proyectos de vida según sus intereses, necesidades, habilidades y conocimientos; pero la población que recurre a la migración para construir un proyecto de vida, en este caso, personas menores de edad que se incorporan a la fuerza laboral internacional, son parte de la niñez y juventud 
invisibilizadas, ya que no calzan en ninguna de las áreas temáticas que tradicionalmente se han usado para visibilizar la participación de la población infanto-juvenil en la historia de la sociedad latinoamericana.

Aunado a esto, lo que anteriormente se ha expuesto como Moratoria Social, no debe leerse solo como un mecanismo para reorganizar social y laboralmente a la población, sino que debe verse como una ganancia dentro de las luchas sociales de la niñez y juventud para tener un periodo de vida, que con el tiempo, se ha reconocido como propio y necesario para que esta población pueda dedicar tiempo y esfuerzo para desarrollar capacidades y habilidades, que les permita sentirse realizados en su niñez y juventud, y que a su vez, les sirva para plantearse un proyecto de vida. Por tanto, es un periodo que propone garantizar el desarrollo de actividades como el juego, el aprendizaje y la socialización entre pares, además del cuido y protección por parte del Estado, comunidad y adultos/as encargados/as para asegurar su integridad física, emocional, económica y sociocultural.

No obstante, en vez de ser un derecho garantizado, se ha convertido en un privilegio para hijos e hijas de quienes tienen los medios y recursos necesarios para garantizar tal moratoria, mientras que aquellos/as niños, niñas y jóvenes que no tienen tales recursos deben vivir bajo condiciones materiales y psicológicas marcadas por la incertidumbre, así como tomar decisiones dentro de un espectro restringido de oportunidades, dentro de las cuales, la migración puede presentarse como mejor opción.

Como lo explica Benedicto (2011), una característica distintiva de la identidad de las juventudes en la actualidad es la incertidumbre "[...] la vida juvenil está marcada por una sensación de desconcierto sobre los caminos a seguir y sobre los resultados que se conseguirán al final del proceso de transición" (p. 29), esto se da como producto de las transformaciones en los estándares o en los puntos de salida y llegada que marcaban la transición de una etapa de la vida a otra, así como la progresiva pérdida de poder de agentes socializadores tradicionales homogenizantes y violentos (religión, familia nuclear, escuela, trabajo, etc.) que se han usado para normalizar lo que debe ser o no ser la vida de las personas jóvenes, además de la agudización de las desigualdades socioeconómicas que limitan el rango de oportunidades para los grupos sociales más pauperizados y amenazados por diferentes expresiones de la violencia estructural.

En el proceso de construcción de proyectos de vida o rutas biográficas, las niñas, los niños y las personas jóvenes deben tomar decisiones dentro las opciones que tienen a mano, para algunas personas son más reducidas, pero, de alguna manera, socialmente se espera que lleguen a consolidar de manera efectiva procesos de autonomía y emancipación, el problema es que las sociedades cada vez más individualistas retiran las responsabilidades de la red de instituciones y entes sociales-estatales que deberían dar respuesta a las poblaciones más excluidas, transfiriendo a las personas jóvenes la 
responsabilidad de la consecución de logros, así como las experiencias de fracaso (Benedicto, 2011).

Cuando hay una sensación de fracaso o cuando existen situaciones estructurales que limitan el desarrollo de las personas, claramente, se puede producir lo que Reguillo (2010, siguiendo lo planteado por Bauman, 2001) llama "la inadecuación biográfica del yo" la cual se explica como "[...] la autopercepción del sujeto de que es responsable, de manera individual y a partir de sus propias decisiones, de su condición de vida; es él o ella, quien resulta inadecuado (o inadecuada) para el orden social" (Reguillo, 2010, p. 400), lo cual puede llevar a la frustración, depresión, ira hacia sí mismo/a, afectando al propio cuerpo, a la propia percepción. Así, niños, niñas y personas jóvenes inmigrantes, al sentir o experimentar fracaso en su proceso de migración, integración y reconstrucción del proyecto de vida, en vez de demandar a la sociedad acciones, apoyo, corresponsabilidades, pueden llegar a culparse a sí mismos/as por su situación o bien sentirse perdidos o excluidos de las oportunidades, viendo así entorpecido su desarrollo personal, social, económico, político, cultural.

Si a las demandas de autonomía y emancipación que se les imponen a las juventudes, se les suma la carga desarrollista propuesta desde las teorías clásicas de migración que responsabilizan a los propios migrantes de compensar - con su trabajo y las remesas- los efectos socioeconómicos producto de la globalización neoliberal, es posible comprender que la población infanto-juvenil inmigrante trabajadora, así como sus familias, se encuentran ante un contexto sociopolítico y legal negligente y de explotación solapada que se aprovecha de su invisibilidad como parte de la fuerza de trabajo internacional.

Finalmente, resulta de interés rescatar que es hasta el 2013 cuando el Consejo Nacional de Migración publica la "Política Migratoria Integral para Costa Rica" para el periodo 2013-2023, desde la cual se empiezan a proponer acciones para la atención de algunas de las necesidades básicas insatisfechas aquí expuestas; a pesar de esto, hasta la fecha no se cuenta con un reglamento que respalde dicha política, por tanto, aunque en dicha política se encuentra que dentro de las propuestas de acción se hace referencia a establecer protocolos para facilitar el acceso en salud, así como una amplia estrategia en el área de educación e, igualmente, se propone "Identificar formas de explotación laboral, erradicar el trabajo infantil en población migrante y regularizar el trabajo permitido de adolescentes migrantes" (Valverde, 2013, p. 59), aún no se tiene un reglamento que dicte cómo debe cumplirse tal política. Por ello, es necesario tener presente que las acciones emprendidas por las diversas instancias implicadas pueden resultar meramente paliativas o reactivas ante eventualidades, ya que las ideologías del desarrollo desigual son las que siguen rigiendo la política nacional e internacional; es decir, mientras exista el desarrollo desigual, 
basado en ideales colonialistas, capitalistas y patriarcales, los movimientos poblacionales de personas jóvenes en busca de mejores condiciones de vida y mejores condiciones laborales, seguirán agudizándose y para entonces las políticas sociales preventivas podrían llegar a ser insuficientes y las correctivas para dar respuesta integral requerirían de un mayor esfuerzo institucional.

Mientras se obtienen los primeros resultados de la "Política Migratoria Integral para Costa Rica" (Valverde, 2013), es necesario seguir visibilizando la imposibilidad del desarrollo de proyectos de vida que respondan a las diversas infancias y juventudes, así como la dificultad que conlleva la satisfacción de necesidades básicas en contextos donde la estrategia expansionista del capital y el neoliberalismo permiten la generación de una nueva división internacional del trabajo dentro de la cual, la mano de obra migrante infanto-juvenil bajo condiciones laborales desreguladas, es fundamental para el crecimiento del capital.

\section{Bibliografía}

Acuña-González, G. (2010). Migración de niños, niñas y adolescentes, derechos humanos y trabajo infantil. Los nuevos actores en la migración y su incorporación al mercado de trabajo en la región: algunos elementos para su análisis. Plataforma Subrregional sobre trabajo infantil y adolecente. Costa Rica: Defensa de Niñas y NiñosInternacional, DNI.

Bauman, Z. (2001). La sociedad individualizada. Madrid: Cátedra.

Benedicto, J (2011). Construyendo la ciudadanía juvenil. Marco teórico para las políticas de juventud y ciudadanía. Barcelona: Diputación de Barcelona.

Brenes, M., Paniagua, L. y Sandoval, C. (2012). La dignidad vale mucho. Mujeres nicaragüenses forjan derechos en Costa Rica. San José, Costa Rica: Editorial UCR.

Cabrera-Duarte, M. A. y Valdéz-Gardea, G.C. (2013). La niñez migrante: un sector que demanda mayor atención pública. En G. Córdova Bojórquez, J. Dutram Hansen, B. E. Lara Enríquez, J. G. Rodríguez Gutiérrez (coord.). Desarrollo humano transfronterizo: retos y oportunidades en la región Sonora-Arizona (pp. 349-369). Hermosillo, Sonora, México: Colegio de Sonora, Universidad de Sonora, El Colegio de la Frontera Norte y Universidad Estatal de Sonora. 
Delgado-Wise, R.; Márquez-Covarrubias, H.; Rodríguez-Ramírez, H. (2009). Seis tesis para desmitificar. El nexo entre migración y desarrollo. Migración y Desarrollo. Red Internacional de Migración y Desarrollo. (12), 27-52.

Dirección de Migración y Extranjería. (2011). Costa Rica Residentes Permanentes, Residentes Temporales y Categorías Especiales Según Continente y País Datos Acumulados Hasta El 30 De Junio 2011. Recuperado http://www.migracion.go.cr/institucion/estadisticas_documentos.html/

Dirección de Migración y Extranjería. (2012). Costa Rica. Refugiados según país. Datos Acumulados hasta el 31 de diciembre, 2012. Recuperado de http://www.migracion.go.cr/institucion/estadisticas_documentos.html/

Defensa de la Niñez Internacional. (2006). Situación del trabajo infantil y adolescente en Centroamérica (Costa Rica, El Salvador, Guatemala, Honduras y Nicaragua). Audiencia ante la Comisión Interamericana de Derechos Humanos.

Instituto Nacional de Estadística y Censos. (2011a). Sistema REDATAM. $X$ Censo Nacional de Población y VI de Vivienda 2011, Costa Rica. Recuperado de: http://www.inec.go.cr/cgibin/RpWebEngine.exe/PortalAction? $\underline{\text { \&ASE }=2011 / 1}$

Instituto Nacional de Estadística y Censos. (2011b) Clasificación De Actividades Económicas De Costa Rica (CAECR-2011). Estructura y notas explicativas. Volumen 1. [pdf]. Recuperado de http://www.inec.go.cr/rpsite/RpHelp/Helpcenso2011/Manual\%20del $\% 20$ censista/Clasificacion_Actividad\%20Economica_Costa\%20Rica \%202011\%20-\%20Vol\%20I.pdf/

Girón-Solórzano, C. L. (2014). Actualización: Diagnóstico nacional sobre la situación de niños, niñas y adolescentes migrantes no acompañados, en el proceso migratorio. Guatemala: UNICEF.

Jiménez-Matarrita, A. (ed.). (2011). Estado de la Niñez y la Adolescencia Migrante. Derechos $y$ desarrollo humano de niñas, niños $y$ adolescentes nicaragüenses en Costa Rica. San José, Costa Rica: MAEC-AECID, UNICEF-COSTA RICA.

Código de la Niñez y Adolescencia (1998). Ley N 7739 Código De La Niñez y La Adolescencia. La Gaceta $N^{\circ} 26$ de 6 de febrero de 1998. Costa Rica: La Gaceta N² 26 de 6 de febrero de 1998. 
Código de la Niñez y Adolescencia (2009). Ley No 8764 General De Migración Y Extranjería. Costa Rica: La Gaceta No 170 de $1^{\circ}$ de setiembre de 2009.

Massey, D., Arango, J., Graeme, H., Kouaouci, A., Pellegrino, A., y Taylor, J. E. (2000). Teorías sobre la migración internacional. Una reseña y una evaluación. Revista Trabajo. Año 2 (No.3). 5-50.

Méndez-Fonseca, F. y Trejos-Solórzano, J. (s.f.). Costa rica: un mapa de carencias críticas para el año 2000. [pdf]. Recuperado de http://ccp.ucr.ac.cr/bvp/pdf/censo2000/libro-censo/2.3-

MendezTrejos.doc.pdf/

Morales-Gamboa, A. (2008). Inmigración en Costa Rica: características sociales y laborales, integración y políticas públicas. Serie Población y Desarrollo $N^{\circ}$ 85. Santiago de Chile, Chile: CEPAL.

Organización Internacional del Trabajo. (1999a). Convenio $N^{\circ} 182$. Sobre la prohibición de las peores formas de trabajo infantil. Recuperado de http://www.ilo.org/public/spanish/standards/relm/ilc/ilc87/com-chic.htm/

Organización Internacional del Trabajo. (1999b). R190-Recomendación sobre las peores formas de trabajo infantil. Recuperado de http://www.ilo.org/dyn/normlex/es/f?

p=NORMLEXPUB:12100:0::NO::P12100_ILO_CODE:R190/

OITOficina Regional para América Latina y el Caribe. (2006). Panorama Laboral 2005. América Latina y el Caribe. (1. ${ }^{a}$ edición). Lima: OIT. Recuperado http://www.ilo.org/americas/publicaciones/WCMS_186765/lang-es/index.htm/

Pérez-Islas, J. A. (2000). Visiones y versiones. Jóvenes, instituciones y políticas de juventud. En L. E. Carvajal G. (Ed.). Umbrales. Cambios culturales, desafíos nacionales y juventud. Medellín: Corporación Región.

Ley General de Migración y Extranjería (2011). Reglamento N³6695-G. para la Aplicación de la Ley General de Migración y Extranjería número 8764 a las Personas Menores de Edad. Costa Rica:La Gaceta № 133 de 11 de julio de 2011.

Reguillo, R. (2003). Jóvenes y estudios culturales. Notas para un balance reflexivo. En Valenzuela, J. M. (Coord). Los Estudios culturales en México. México: Fondo de Cultura Económica. 
Reguillo, R. (2010). La condición juvenil en el México contemporáneo. Biografías, incertidumbres y lugares. En Reguillo, R. (coord.). (2010). Los jóvenes en México. México: Fondo de Cultura Económica.

Rodríguez, E. (2011). Políticas de juventud y desarrollo social en América Latina: bases para la construcción de respuestas integradas. San Salvador: UNESCO.

Ruiz-Peralta, L. F.; García-Cárdenas, E. (2015). Reseña. Gloria Ciria Valdez Gardea (coord.), (2012), Movilización, migración y retorno de la niñez migrante. Una mirada antropológica. Región y Sociedad vol. XXVII, núm. 63, mayo-agosto, 2015, pp. 299-309

Valenzuela, J. M. (2009). El futuro ya fue. Socioantropología de I@s jóvenes en la modernidad. México, D.F: El Colegio de la Frontera Norte/Casa Juan Pablos.

Valenzuela, J. M. (2010). Juventudes demediadas. Desigualdad, violencia y criminalización de los jóvenes en México. En Reguillo, R. (coord.). (2010). Los jóvenes en México. México: Fondo de Cultura Económica.

Valverde-Rojas, J. M. (coord.). (2013). Política migratoria integral para Costa Rica. San José, Costa Rica: Consejo Nacional de Migración, Dirección General de Migración y Extranjería.

World Vision (2015) Motivos de Migración de la Niñez y Juventud en 27 Municipios de El Salvador. [pdf] Recuperado de http://www.redhum.org/uploads/documentos/pdf/Redhum_SV_Estudio_ Exploratorio_ninez_migrante_no_acompanada_WVI_oct2014_vf20141020-IA-15611.pdf/ 